\title{
MicroRNA-200a suppresses migration and invasion and enhances the radiosensitivity of NSCLC cells by inhibiting the HGF/c-Met signaling pathway
}

\author{
MENGHUA DU ${ }^{1,3}$, JIN WANG $^{1},{\text { HUAN } \mathrm{CHEN}^{1}, \text { SHOULI WANG }}^{2}$, \\ LIESONG CHEN ${ }^{1}$, YICHANG XU ${ }^{2}$, FENGTAO SU ${ }^{3}$ and XUEGUAN LU ${ }^{1,4}$ \\ ${ }^{1}$ Department of Oncology and Radiotherapy, The Second Affiliated Hospital of Soochow University; \\ ${ }^{2}$ Department of Pathology, School of Biology and Basic Medical Sciences, Soochow University, Suzhou, \\ Jiangsu 215123; ${ }^{3}$ Cancer Institute, Department of Radiation Oncology, Fudan University Shanghai Cancer Center; \\ ${ }^{4}$ Department of Radiation Oncology, Fudan University Shanghai Cancer Center, Shanghai 200032, P.R. China
}

Received May 1, 2018; Accepted November 28, 2018

DOI: $10.3892 / o r .2018 .6925$

\begin{abstract}
Hepatocyte growth factor (HGF), an activator of the c-Met signaling pathway, is involved in tumor invasiveness, metastasis and radiotherapy resistance. In the present study, a novel HGF regulatory pathway in lung cancer involving microRNAs (miRNAs/miR) is described. Immunohistochemical staining and western blot analyses demonstrated that HGF was upregulated and associated with miR-200a downregulation in non-small cell lung cancer (NSCLC) samples compared with normal lung tissues. The association between HGF and miR-200a was associated with the degree of tumor malignancy and cell migration and invasion. miR-200a negatively regulated HGF expression by targeting the 3'-untranslated region of the HGF mRNA. miR-200a overexpression induced HGF downregulation, decreased NSCLC cell migration and invasion, promoted apoptosis, and decreased cell survival in A549 and H1299 cells in response to ionizing radiation. The present results revealed a previously uncharacterized role of miRNA-200a in regulating tumor malignancy and radiosensitivity by suppressing HGF expression, a key factor in the $\mathrm{HGF} / \mathrm{c}-\mathrm{Met}$ pathway.
\end{abstract}

\section{Introduction}

Lung cancer is the second most common cancer and the leading cause of cancer-associated mortality, with an overall

Correspondence to: Dr Fengtao Su, Cancer Institute, Department of Radiation Oncology, Fudan University Shanghai Cancer Center, 270 Dong'an Road, Xuhui, Shanghai 200032, P.R. China

E-mail:sufengtao@126.com

Professor Xueguan Lu, Department of Radiation Oncology, Fudan University Shanghai Cancer Center, 270 Dong'an Road, Xuhui, Shanghai 200032, P.R. China

E-mail: luxueguan@163.com

Key words: lung cancer, miRNA-200a, hepatocyte growth factor/ c-met signal pathway, radiosensitivity 5-year survival rate of $15 \%$ (1-3). Non-small cell lung cancer (NSCLC) accounts for $\sim 85 \%$ of all lung cancer cases and $\sim 70 \%$ of patients with NSCLC have locally advanced disease or distant metastases at the time of diagnosis (4). The prognosis of patients with NSCLC remains poor and most patients die from hematogenous dissemination, whereas certain patients die from local organ failure. Therefore, improving the understanding of the molecular mechanisms underlying NSCLC development and progression is necessary to design effective therapies for this disease.

Hepatocyte growth factor (HGF) and its receptor tyrosine kinase c-Met are overexpressed in a variety of types of human cancer, including NSCLC, renal, breast, ovarian cancer and pleural mesothelioma (5). High levels of expression of HGF represent an unfavorable prognostic factor $(6,7)$. The activation of the $\mathrm{HGF} / \mathrm{c}$-Met signaling pathway promotes invasiveness and distant metastasis in cancer $(5,8)$ and increases tumor radioresistance (9). In the cell microenvironment, HGF is produced from the same cell (autocrine loop), neighboring cells (paracrine loop), or distant organs (endocrine loop) $(10,11)$. By targeting its receptor c-Met, HGF activates auto-phosphorylation in the catalytic domain. c-Met in turn activates a series of signaling pathways including Ras/extracellular signal regulated kinase and phosphoinositol 3 kinase/protein kinase B. Therefore, HGF and c-Met interaction and expression are precisely monitored under physiological and pathological conditions. Aberrant HGF/Met signaling activates phosphorylation cascades, resulting in a comprehensive rewiring of gene expression patterns and promoting tumor migration, invasion and metastasis $(12,13)$.

MicroRNAs (miRNAs/miRs), a class of small non-coding RNAs, post-transcriptionally and/or translationally regulate gene expression by binding to the 3'-untranslated region (3'-UTR) of their target genes $(14,15)$. Approximately one third to one half of human genes are regulated by miRNAs, each of which has a number of target transcripts (16). miRNAs are involved in a wide range of human physiological and pathological processes, including tumorigenesis $(17,18)$. miRNAs can function as oncogenes or tumor suppressors $(19,20)$. 
Studies have demonstrated that miR-200c, miR-193a-3p and miR-193a-5p inhibit the proliferation, migration and invasion of NSCLC cell lines $(21,22)$. Furthermore, re-expression of miR-451 significantly reverses the radioresistance of docetaxel-resistant lung adenocarcinoma cells by promoting apoptosis and DNA double stranded breaks (23). miRNAs are suggested as potential targets to enhance radiosensitivity in cancer. In the present study, miRNAs capable of enhancing the radiosensitivity of NSCLC cells by negatively regulating HGF expression were investigated. miR-200a, located on chromosome $1 \mathrm{p} 36.33$, is involved in cell proliferation and migration by targeting Kelch-like ECH-associated protein 1, Gail and $\beta$-catenin. miR-200a downregulation is associated with hepatic fibrosis, human retinoblastomas, human glioma and breast cancer (24-26).

In the present study, the expression of HGF and miRNAs was analyzed in NSCLC and normal tissues. Analysis of clinicopathological data confirmed that HGF and miR-200a are associated with tumor progression and the response to therapy. Bioinformatics analysis and biological experiments demonstrated that miR-200a negatively regulated HGF expression, thereby decreasing NSCLC cell invasion and metastasis. The miR-200a/HGF pathway also affected the radiosensitivity of NSCLC. These results indicated that the miR-200a-mediated negative regulation of HGF is involved in NSCLC invasion and metastasis at the cellular and clinical levels.

\section{Materials and methods}

Tissue collection. Fresh tumor samples and adjacent normal tissues were obtained from 11 patients who had undergone surgery at the Second Affiliated Hospital of Soochow University (Suzhou, China) between September 2016 and June 2017. Patients were aged between 45-65, of whom 4 were female and 7 male. The pathological diagnosis of all patients was NSCLC prior to surgery and no patients received anticancer treatment prior to the operation. All tissue samples were stored at $-80^{\circ} \mathrm{C}$. The present study was approved by the Ethics Committee of the Second Affiliated Hospital of Soochow University and written informed consent was provided by all patients.

Immunohistochemical (IHC) staining. IHC staining was performed by a two-step procedure. Upon rehydration in anhydrous ethanol for $5 \mathrm{~min}, 95 \%$ ethanol for $5 \mathrm{~min}, 85 \%$ ethanol for $5 \mathrm{~min}, 75 \%$ ethanol for $5 \mathrm{~min}$, the slides were washed 3 times in tap water, and then a phosphate-buffered saline (PBS) solution was used 3 times for 5 min each time. A three-way dip wax was used as a fixative, at $56-58^{\circ} \mathrm{C}$, for $\sim 3 \mathrm{~h}$, and finally embedded in a wax block casette, the continuous slice thickness is $3 \mu \mathrm{m}$. The slides were subjected to antigen retrieval by pressure-cooking at $92-98^{\circ} \mathrm{C}$ for $15 \mathrm{~min}$. Endogenous peroxidase activity was neutralized using peroxide block placement on the slides for $10 \mathrm{~min}$ at room temperature. The slides were then incubated with anti-HGF polyclonal antibody (dilution 1:200; cat. no. ab83760; Abcam, Cambridge, MA, USA) at $4^{\circ} \mathrm{C}$ overnight. This was followed by incubation with peroxidase-conjugated polymer (ChemMate EnVision/horseradish peroxidase; Gene Tech Biotechnology Co., Ltd., Shanghai, China) for $30 \mathrm{~min}$ at room temperature. The chromogen reaction was developed in 3'-diaminobenzidine (DAB; Gene Tech Biotechnology Co., Ltd.) tetrahydrochloride for $5 \mathrm{~min}$ at room temperature. Finally, hematoxylin was performed for $30 \mathrm{sec}$ at room temperature used as a light nuclear counterstain.

The percentage of positive-staining cells was graded on a scale of $0-3$, with $<5 \%$ positive-staining cells as grade 0 , $5-25 \%$ as grade $1,26-50 \%$ as grade 2 and $>50 \%$ as grade 3 . The intensity of staining was also graded on a scale of $0-2$, with negative to weak intensity as grade 0 , weak-moderate intensity as grade 1 and moderate to strong intensity as grade 2 . Finally, the percentage and intensity scores were multiplied. The final score between 0-2 was determined as low expression and a score higher than 2 was determined as high expression.

miRNA screening. The targetscan.org and microrna.org websites were used to screen miRNAs. Firstly, human species was selected and HGF was entered as the target gene in TargetScan. This identified eight broadly conserved 8-mer predicted target sites, including miR-200a-3p, miR-141-3p, miR-26-5p, miR-199-5p, miR-19-3p, miR-101-3p.1, miR-204-5p and miR-211-5p. Then, in the mircorna.org website, after entering HGF as target mRNA and selecting Homo sapiens, 29 miRNAs were displayed and ordered by the sum of mirSVR scores, including miR-200a, miR-141, miR-495 and miR-1297 among others. The results of the two sites were then matched, finally selecting miR-200a and miR-141 for subsequent experiments.

Cell culture. The parental human lung adenocarcinoma cell lines (A549 and H1299) were obtained from the Cell Bank of Shanghai Institute of Cell Biology (Chinese Academy of Medical Sciences, Shanghai, China). A549 and H1299 cells were grown in Dulbecco's modified Eagle's medium (DMEM; Corning, Inc., Corning, NY, USA) containing 10\% certified fetal bovine serum (FBS)-heat inactivated (Biological Industries, Kibbutz Beit Haemek, Israel), penicillin (100 U/ml), and streptomycin $(100 \mathrm{U} / \mathrm{ml})$ and maintained in an incubator at $37^{\circ} \mathrm{C}$ with $5 \% \mathrm{CO}_{2}$ in a humidified atmosphere.

Western blot analysis. Briefly, NSCLC tissues milled into powder in liquid nitrogen or A549 and H1299 cells were extracted using radioimmunoprecipitation assay cell lysis reagent containing proteinase and phosphatase inhibitors (Beyotime Institute of Biotechnology, Haimen, China) at $4^{\circ} \mathrm{C}$ for $30 \mathrm{~min}$. Cell lysates were centrifuged at $12,000 \mathrm{x} \mathrm{g}$ for $20 \mathrm{~min}$ at $4^{\circ} \mathrm{C}$ and the protein concentrations of the supernatant were determined using the bicinchoninic acid protein assay kit (Beyotime Institute of Biotechnology). The supernatants containing total protein were then mixed with a corresponding volume of $5 \mathrm{X}$ SDS loading buffer and heated at $100^{\circ} \mathrm{C}$ for $10 \mathrm{~min}$. Then, the supernatant lysates were run on $10 \%$ SDS-polyacrylamide gels (50 $\mu \mathrm{g} / \mathrm{lane})$ and proteins were transferred to polyvinylidene fluoride (PVDF) membranes (EMD Millipore, Billerica, MA, USA) by semidry electroblotting $\left(1.5 \mathrm{~mA} / \mathrm{cm}^{2}\right)$. PVDF membranes were then incubated in blocking buffer [Tris-buffered saline (TBS) supplemented with $0.05 \%$ (vol $/ \mathrm{vol}$ ) Tween-20; TBST] containing $5 \%$ (wt/vol) skimmed milk powder for $2 \mathrm{~h}$ at room temperature followed by three 10-min washes in TBST. The PVDF membranes were then incubated with anti-HGF (dilution 1:1,000; cat. no. ab83760 Abcam) or anti-c-Met (dilution 1:1,000; 
cat. no. ab74217; Abcam) as internal normalizers in TBST containing $5 \%$ (wt/vol) skimmed milk powder (antibody buffer) overnight at $4^{\circ} \mathrm{C}$ on a three-dimensional rocking table. Then, the membranes were washed three times for $10 \mathrm{~min}$ in TBST and incubated with goat anti-rabbit IgG conjugated to horseradish peroxidase (dilution 1:1,000; cat. no. A0208; Beyotime Institute of Biotechnology) in antibody buffer for $2 \mathrm{~h}$. Finally, membranes were washed three times for $10 \mathrm{~min}$ in TBST and exposed to ECL Advanced reagent (EMD Millipore) for $2 \mathrm{~min}$ as described in the manufacturer's protocol. Membranes were exposed to Hyperfilm-ECL for 2-5 min and visualized using a Fluor S Multimager and Quantity One 4.1 (Gene Company, Ltd., Hong Kong, China). The molecular weights of the bands were calculated by comparison with prestained molecular weight markers (molecular weight range, 6,500-250,000) that were run in parallel with the samples. Semiquantitative analysis of specific immunolabeled bands was performed using a Fluor S image analyzer and Quantity One 4.1 (Gene Company, Ltd.)

Reverse transcription-quantitative polymerase chain reaction (RT-qPCR) analysis. Total RNA from cultured cells was extracted using the TRIzol reagent (Invitrogen; Thermo Fisher Scientific, Inc., Waltham, MA, USA) according to the manufacturer's protocol. miRNA levels were measured by RT-qPCR. Total RNA was subsequently reverse transcribed at $65^{\circ} \mathrm{C}$ for $5 \mathrm{~min}$ to cDNA with the stem-loop reverse transcription primer (Beijing Genomics Institute, Beijing, China) for HGF and miR-200a detection. Then PCR was performed out in a PCR gene amplification apparatus: $42^{\circ} \mathrm{C}$ for $60 \mathrm{~min}, 70^{\circ} \mathrm{C}$ for $5 \mathrm{~min}$, and then the reaction was terminated, placed on ice for storage or stored at $-20^{\circ} \mathrm{C}$. The primer sequences are: HGF qPCR-forward primer, 5'-CAACAAACTTAGCTCATCGCA A-3' and HGF qPCR-reverse primer, 5'-GCCTGGGTGAAA GAATCCT-3'; GAPDH qPCR-forward primer, 5'-CAAGGT CATCCATGACAACTTTG-3' and GAPDH qPCR-reverse primer, 5'-GTCCACCACCCTGTTGCTGTAG-3'; miR-200a RT: 5'-GTCGTATCCAGTGCGTGTCGTGGAGTCGGC AAT TGCACTGGATACGACACATCGT-3'; miR-200a qPCR-forward primer, 5'-GGGGTAACACTGTCTGGTAG-3' and miR-200a qPCR-reverse primer, 5'-TGCGTGTCGTGG AGTC-3'; U6 forward primer, 5'-GCTTCGGCAGCACAT ATACTAAAAT-3' and reverse primer, 5'-CGCTTCACGAAT TTGCGTGTCAT-3'.

qPCR was carried out using SYBR Premix Ex Taq ${ }^{\text {TM }}$ (Takara Biotechnology, Co., Ltd., Dalian, China). qPCR thermocycling was performed according to the following: Pre-deformation $95^{\circ} \mathrm{C}$ for $10 \mathrm{~min}, 1$ cycle; denaturation $95^{\circ} \mathrm{C}$ for $15 \mathrm{sec}$ and annealing $60^{\circ} \mathrm{C}$ for $60 \mathrm{sec}, 40$ cycles. The reactions were placed in a 96-well plate using a preheated real-time instrument (ABI 7500HT; Applied Biosystems Life Technologies; Thermo Fisher Scientific, Inc.). The relative levels of expression were quantified and analyzed using Bio-Rad iCycler iQ software 3.1 (Bio-Rad Laboratories, Inc., Hercules, CA, USA). Cq values were used to calculate the RNA expression levels. The amount of miR-200a expression $\left(2^{-\Delta \Delta \mathrm{Cq}}\right)$ (27) was normalized using the endogenous U6 reference.

In situ hybridization (ISH) staining. Sections of 1-3 $\mu \mathrm{m}$ thickness were cut from paraffin-embedded tissues to evaluate
miR-200a expression by ISH. In brief, the slides were incubated at $60^{\circ} \mathrm{C}$ for $2 \mathrm{~h}$, deparaffinized in xylene and rehydrated with graded alcohol washes. Slides were then washed three times with diethyl pyrocarbonate-treated PBS, digested with $5 \mu \mathrm{g} / \mathrm{ml}$ proteinase $\mathrm{K}$ at $37^{\circ} \mathrm{C}$ for $30 \mathrm{~min}$ and washed and dehydrated in graded alcohol. Slides were hybridized at $55^{\circ} \mathrm{C}$ for $2 \mathrm{~h}$ with $50 \mathrm{nmol} / 1$ locked nucleic acid-modified digoxigenin-labeled probes for miR-200a (Wuhan Boster Biological Technology, Ltd., Wuhan, China): miR-200a Probe sequence: 5'-ACATCG TTACCAGACAGTGTTA-3'.

Following stringency washes ( $5 \mathrm{X}, 1 \mathrm{X}$ and $0.2 \mathrm{X}$ SSC), slides were placed in blocking solution for $1 \mathrm{~h}$ at room temperature followed by incubation in alkaline phosphatase conjugated anti-DIG Fab fragment solution at $37^{\circ} \mathrm{C}$ for $1 \mathrm{~h}$. Slides were incubated in Strept Avidin-Biotin Complex-fluorescein isothiocyanate (FITC; 1:100; Wuhan Boster Biological Technology, Ltd.) at $37^{\circ} \mathrm{C}$ for $30 \mathrm{~min}$, washed three times and directly observed by fluorescent microscopy, with positive regions indicated by yellow or green.

The intensity histoscore with the following categories according to Donahue's description was used: 0 , negative, 1 , weakly positive, 2 , moderately positive and 3 , strongly positive. The final score between 0-1 was determined as low expression and a score of 2-3 was determined as high expression.

Transfection of miRNA and siRNA. Human antisense miR-200a mimics and mimic negative control were purchased from Guangzhou Ribobio Co., Ltd., (Guangzhou, China): Human antisense miR-200a mimic: 5'-UAACACUGUCUGGUAACG AUGUAUCGUUACCAGACAGUGUUAUU-3'. Negative control: 5'-UUCUCCGAACGUGUCACGUTTACGUGACAC GUUCGGAGAATT-3'.

Human antisense miR-200a mimic and mimic negative control were referred to as miR-200a and mimic con, respectively. Complete medium without antibiotics was used to culture the cells at least $24 \mathrm{~h}$ prior to transfection. The cells were washed with $1 \mathrm{X}$ PBS (pH 7.4) and then transiently transfected with $100 \mathrm{nM}$ miR-200a mimic or mimic con using Lipofectamine $^{\mathrm{TM}} 2000$ (Invitrogen; Thermo Fisher Scientific, Inc.) according to the manufacturer's protocol.

A total of three siRNA duplexes targeting human HGF were designed and synthesized by Guangzhou RiboBio Co., Ltd. The effective siRNA target sequence was 5'-GCAGAG GGACAAAGGAAAA-3'. Negative control siRNA: 5'-UUU TGATCAUTGATGAAA-3'.

For transfection, the cells were plated on an antibiotic-free growth medium at $60 \%$ confluence $\sim 24 \mathrm{~h}$ prior to transfection. RNA oligonucleotides were transfected at a final concentration of $100 \mathrm{nM}$, using Lipofectamine ${ }^{\mathrm{TM}} 2000$ (Invitrogen; Thermo Fisher Scientific, Inc.) according to the manufacturer's protocol.

Rescue experiment. At $24 \mathrm{~h}$ following siRNA transfection into H1299 cells, HGF was transfected into the cells. Western blot detection of HGF expression was performed after $24 \mathrm{~h}$.

Transwell migration and invasion assays. A549 and H1299 cells were grown in DMEM containing 10\% FBS and transfected with $50 \mathrm{nM}$ miR-200a mimic or negative control, or $50 \mathrm{nM}$ si-HGF or negative control. Following $24 \mathrm{~h}$, the cells 
were harvested by trypsinization and washed once with PBS. To measure cell migration, 8-mm pore size culture inserts (Transwell; Costar; Corning, Inc.) were placed into the wells of 24-well culture plates, separating the upper and the lower chambers. In the lower chamber, $500 \mu 1$ of DMEM containing $10 \%$ FBS was added. Then, serum-free medium containing $5 \times 10^{4}$ cells was added to the upper chamber for migration assays. Invasion assays were performed similarly except Transwells were precoated with $16 \mu \mathrm{g}$ of Matrigel (Corning, Inc.). Cells were incubated at $37^{\circ} \mathrm{C}$ with $5 \% \mathrm{CO}_{2}$ for 24 and $48 \mathrm{~h}$ for migration and invasion, respectively, and cell morphology was observed by staining with $0.1 \%$ crystal violet staining solution was used for $10 \mathrm{~min}$ at room temperature, and observed under light microscope following washing. Filters were washed thoroughly with $1 \mathrm{X}$ PBS. Each experiment was performed at least three times.

Dual-Luciferase reporter assay. Dual-Luciferase reporter assay system was purchased from Promega Corp. (Madison, WI, USA). HGF wild-type and mutant type were generated by Shanghai GenePharma Co., Ltd., (Shanghai, China). The pmirGLO Dual-Luciferase miRNA Target Expression Vector was used (Promega Corp.).

HGF 3'-UTR wild type 5'-CTGTTGTTTTGTTTGTCA GTGTTA-3' HGF and 3'-UTR mutant type 5'-CTGTTGTTT TGTTTGTGCATACAA-3'.

HGF wild-type and mutant (100 ng) were transfected using Lipofectamine $^{\mathrm{TM}} 2000$ (Invitrogen; Thermo Fisher Scientific, Inc.) into H1299 cells together with $100 \mathrm{nM}$ miR-200a mimic into cells. After $36 \mathrm{~h}$, growth media were removed from cultured cells, which were rinsed in $1 \mathrm{X}$ PBS. The rinsing solution was removed and $20 \mu \mathrm{l}$ of $1 \mathrm{X}$ Passive Lysis Buffer was added into each culture vessel of 96-well culture plates, which were agitated for $30 \mathrm{~min}$ at room temperature. Then, $100 \mu 1$ of LAR II was added and firefly luciferase activity was measured using a microplate reader (BioTek Instruments, Inc., Winooski, VT, USA). Then, $100 \mu \mathrm{l}$ of Stop \& Glo reagent was added and Renilla luciferase activity was measured. The cycle was repeated for all wells in the plate. Renilla luciferase (hRluc-neo) was used as a control reporter for normalization and selection.

Clonogenic assay. Cells were transfected with miR-200a mimic or mimic negative control, together with siR-HGF or negative control, as described above. A total of $24 \mathrm{~h}$ later, transfected cells were trypsinized, counted and replated at a density of 300, 500, 800, 1,200 and 2,000 cells/6-cm dish for $0,2,4,6$ and 8 Gy dose irradiation, separately. A total of 10 days later, colonies resulting from the surviving cells were fixed with $4 \%$ paraformaldehyde for $15 \mathrm{~min}$ at room temperature, stained with $0.1 \%$ crystal violet for $20 \mathrm{~min}$ and counted. Colonies containing at least 50 cells were scored under a light microscope. Each assay was performed in triplicate.

Flow cytometric analysis of apoptosis. Flow cytometric analysis of apoptosis was performed with Annexin V-FITC Apoptosis Detection kit (Beyotime Institute of Biotechnology; cat. no. C1063). A549 and H1299 cells transfected with miR-200a mimic or negative control, siRNA HGF or negative control performed as described above. After $24 \mathrm{~h}$, cells were treated with 4 Gy dose irradiation. A total of $48 \mathrm{~h}$ later, cells were trypsinized and resuspended, counted, and $5-10 \times 10^{5}$ cells in $1 \mathrm{X}$ binding buffer were incubated with $5 \mu \mathrm{l}$ of Annexin V-FITC and $10 \mu \mathrm{l}$ propidium iodide (PI) for $15 \mathrm{~min}$ in the dark. Cells were analyzed using a flow cytometer and associated BD FACSuite ${ }^{\mathrm{TM}}$ v1.0.6.5230. (FACSCalibur; BD Biosciences) and FITC-Annexin V-positive and PI-negative cells were considered as apoptotic and the experiments were carried out in triplicates.

Immunofluorescence assay. Cells at 70-80\% confluence were placed on sterilized coverslips directly or $24 \mathrm{~h}$ following transfection. After attachment, cells were treated with irradiation (4.0 Gy). A total of $4 \mathrm{~h}$ later, the cells were fixed in ice-cold acetone for $15 \mathrm{~min}$, washed with PBS and then stained with rabbit anti- $\gamma$-H2AX (dilution 1:200; cat. no. ab2893; Abcam) $1 \mathrm{~h}$ following blocking with $3 \%$ bovine serum albumin (BSA; Beyotime Institute of Biotechnology) for $30 \mathrm{~min}$ at room temperature. After washing, the cells were treated with goat anti-rabbit FITC conjugated secondary antibody (Beyotime Institute of Biotechnology; cat. no. P0176; $1.5 \mu \mathrm{g} / \mathrm{ml}$ ) for $1 \mathrm{~h}$ at room temperature and then counterstained with DAPI (Beyotime Institute of Biotechnology; cat. no. C1005) for $5 \mathrm{~min}$ at room temperature. Images were captured with a fluorescent microscope.

Statistical analysis. All the quantitative data in the present study are expressed as the mean of at least three independent experiments \pm standard error (SE). Comparisons of the control groups and the treated groups were analyzed using the Student's t-test of GraphPad Prism 5 software (Graphpad Software, Inc., La Jolla, CA, USA) and a one-way analysis of variance (ANOVA) with a Fisher's post-hoc test using SPSS statistics 19 software (IBM Corp., Armonk, NY, USA). $\mathrm{P}<0.05$ was considered to indicate a statistically significantly difference.

\section{Results}

HGF expression is significantly associated with NSCLC. $\mathrm{HGF}$ serves a central role in the $\mathrm{HGF} / \mathrm{c}-\mathrm{Met}$ pathway. To gain insight in to the association between HGF and cancer, the expression level of HGF in lung cancer was investigated. IHC analysis of clinical lung cancer tissues (Fig. 1A) demonstrated that the HGF positive ratio was $91 \%$ in lung cancer tissues, compared with $9 \%$ in normal lung tissues $(\mathrm{P}<0.05$; Fig. 1B), indicating that the expression level of HGF was increased in NSCLC compared within normal tissues. Next, the proteins from the above samples were isolated and separated by gel electrophoresis to perform grey value analysis (Fig. 1C). The relative protein expression level was significantly increased in all the lung cancer tissues except 4 compared with normal tissues $(\mathrm{P}<0.05$; Fig. 1D). Western blot analysis confirmed that HGF expression was increased in NSCLC tissues compared within normal lung tissues.

To assess the HGF expression level and activity in vitro, HGF or mock siRNA were transfected and/or co-cultured with HGF in A549 and H1299 NSCLC cells. The results of RT-qPCR demonstrated that the HGF mRNA expression levels were significantly reduced in A549 and H1299 cells (0.06- and 

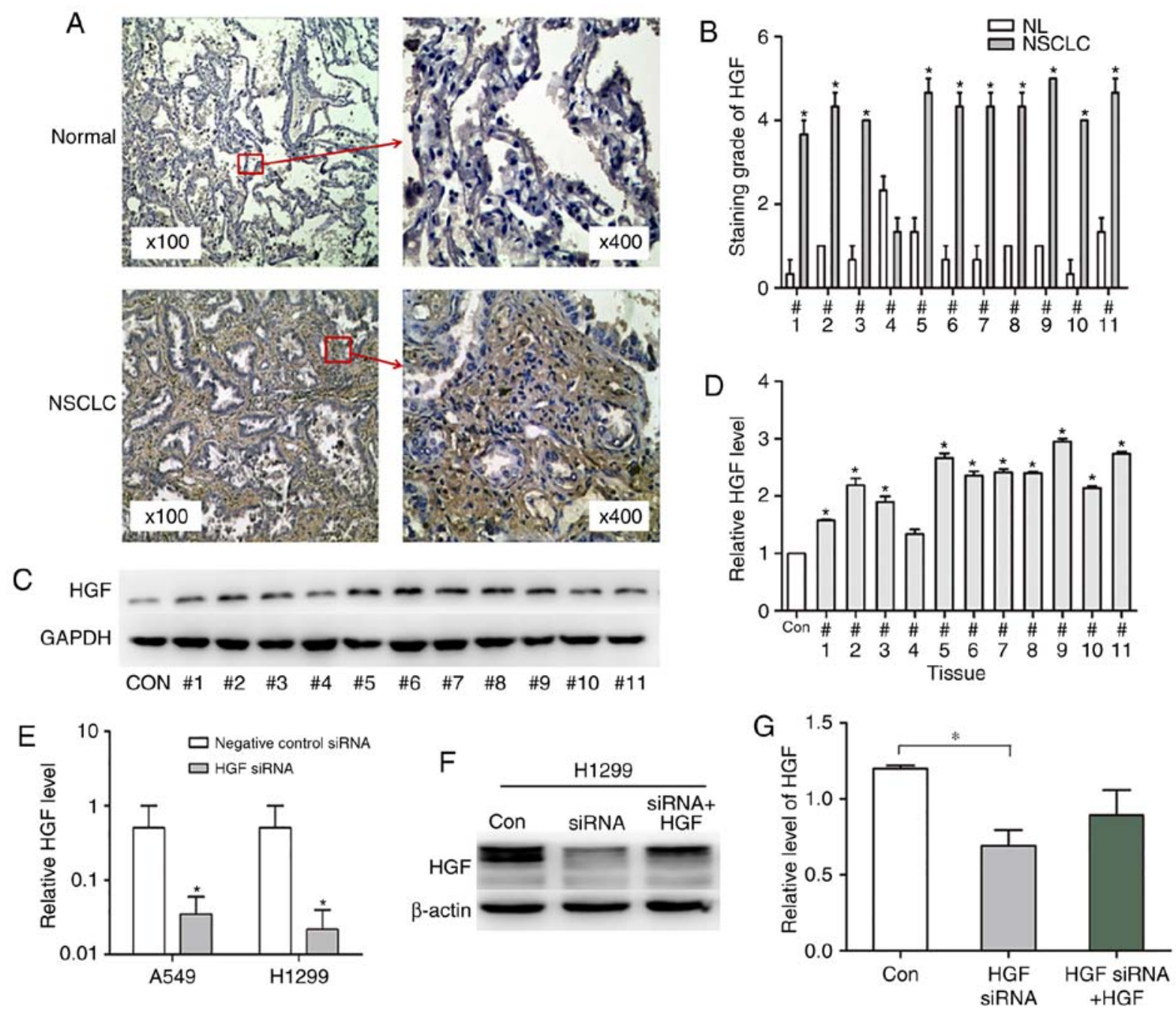

Figure 1. The expression of HGF is higher in lung cancer tissues and cells. (A) Immunohistochemistry staining and (B) quantitative analysis of HGF expression levels in NSCLC samples and normal lung tissues. ${ }^{*} \mathrm{P}<0.05$ NSCLC vs. NL. (C) Western blotting and (D) quantitative analysis of HGF expression levels in NSCLC samples ( $\mathrm{n}=11)$ and normal lung tissues. ${ }^{*} \mathrm{P}<0.05$ NSCLC vs. con. (E) HGF siRNA was transfected into A549 and H1299 cells, which effectively silenced HGF. "P<0.05 HGF siRNA vs. negative control siRNA. (F) Rescue experiment with (G) densitometric analysis demonstrated that transfection of HGF into HGF-silenced H1299 rescued protein expression. "P<0.05 HGF siRNA vs. con; *P $>0.05$ HGF siRNA+HGF vs. con. siRNA downregulates HGF. HGF, hepatocyte growth factor; si, small interfering; NSCLC, non-small cell lung cancer; NL, normal lung; Con, control.

0.04-fold in siRNA HGF and mock; P<0.05; Fig. 1E). Western blot analysis demonstrated similar results, as HGF siRNA reduced the HGF expression level by 0.5 -fold compared with the control group $(\mathrm{P}=0.0086$; Fig. $1 \mathrm{E}$ and $\mathrm{F})$. Treatment with HGF rescued the HGF siRNA effect (Fig. 1F). As presented in the grey value analysis, the HGF protein value decreased from 1 to 0.75 in the HGF plus siRNA group compared with the siRNA alone group. ( $\mathrm{P}=0.14$; Fig. $1 \mathrm{G})$. These results indicated that HGF can be upregulated or downregulated through HGF siRNA or HGF treatment.

Downregulation of HGF expression inhibits NSCLC cell migration and invasion. HGF was upregulated in NSCLC tissues compared with normal tissues, suggesting that HGF upregulation affects lung cancer malignancy. To clarify the role of HGF in tumor migration and invasion, HGF was silenced in NSCLC cells using the siRNA technique and the effect on cell migration and invasion was assessed. A total of $48 \mathrm{~h}$ following transfection of siRNA into A549 and H1299 cells by Lipofectamine 2000, western blot analysis was used to detect the protein expression of HGF and c-Met. As presented in Fig. 2A, HGF siRNA reduced the HGF expression. Grayscale value analysis demonstrated that the expression level of HGF in A549 and H1299 cells was decreased from 1 to $0.63 \pm 0.034$ and $0.14 \pm 0.05$ in the control group and HGF siRNA groups, respectively $(\mathrm{P}<0.05$; Fig. $2 \mathrm{~B})$. In addition, c-Met expression was downregulated in response to HGF knockdown (Fig. 2A). The grey value of c-Met was reduced to 0.28 - and 0.25 -fold in the siRNA group compared with the con group (Fig. 2B), respectively. The migration and invasion of NSCLC cells with silenced HGF were examined by Transwell assay. The transmembrane cell rates of migration and invasion were significantly decreased by 66.9 and $75.7 \%$ in A549 cells (Fig. 2C and D), and by 70.7 and 66.7\% in H1299 cells (Fig. 2E and $\mathrm{F})$, respectively $(\mathrm{P}<0.05)$. These results suggest that $\mathrm{HGF}$ is critical for the malignancy of lung cancer through its effect on migration and invasion.

$H G F$ is the target gene of miR-200a. miRNAs serve important roles in the regulation of the expression of various oncogenes 

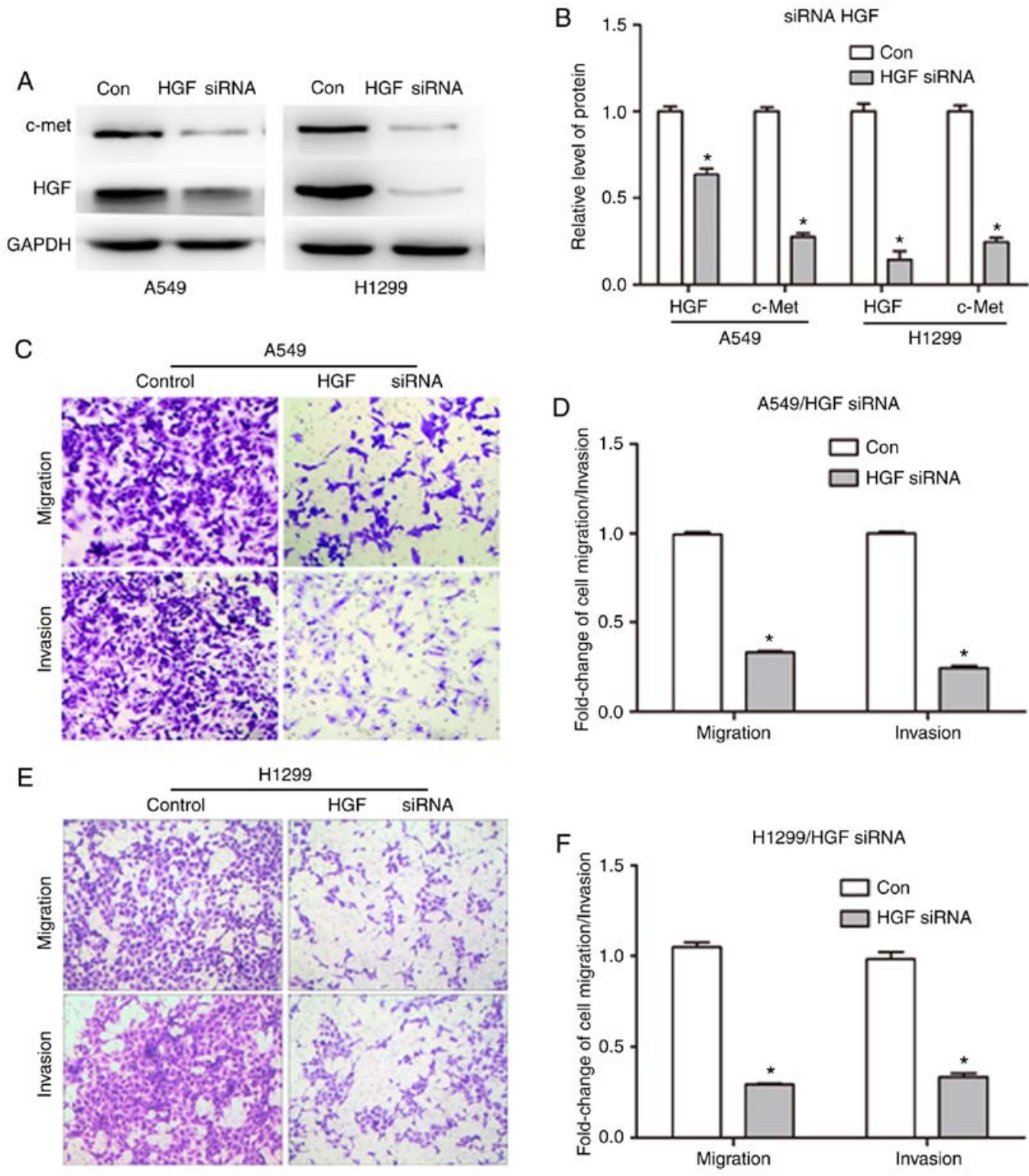

Figure 2. Downregulation of HGF expression inhibits NSCLC cell migration and invasion. (A) Western blotting and (B) quantitative analysis revealed that the expression level of HGF and its receptor c-Met were decreased in A549 and H1299 cells following the transfection of siRNA HGF. ${ }^{*} \mathrm{P}<0.05$ HGF siRNA vs. con. (C) Images (magnification, $\mathrm{x} 40$ ) and (D) quantitative analysis of the Transwell assay which demonstrated that the migration and invasion of A549 cells were inhibited following transfection with HGF siRNA. "P<0.05 HGF siRNA vs. con. (E) Images (magnification, $x 40)$ and (F) quantitative analysis of the Transwell assay demonstrated that the migration and invasion of H1299 cells were inhibited following transfection with HGF siRNA. "P<0.05 HGF siRNA vs. con. HGF, hepatocyte growth factor; si, small interfering; NSCLC, non-small cell lung cancer; Con, control.

by binding to complementary 3'-UTR mRNA sequences. First, the potential miRNAs involved in the regulation of the HGF/c-Met signaling pathway in NSCLC cells were investigated using targetscan.org and microrna.org miRNA database websites. The intersection results demonstrated that the conserved sequences of miR-200a and miR-141 have potential binding sites in the HGF 3 '-UTR mRNA region (Fig. 3A). Secondly, the expression level of the two miRNAs in the NSCLC samples and normal lung tissues $(\mathrm{n}=11)$ were investigated by RT-qPCR to determine whether miR-200a and miR-141 were associated with NSCLC. The results demonstrated that the miR-200a expression level was significantly decreased in NSCLC samples compared with normal lung tissues $(\mathrm{P}<0.05$; Fig. 3B). miR-141 expression levels did not differ significantly between NSCLC and normal lung tissues.
To further confirm the miR-200a distribution and expression in lung cancer, miR-200a expression in lung cancer and normal tissues was examined by ISH (Fig. 3C). The score of miR-200a was significantly lower in NSCLC lung cancer tissues than in normal tissues $(0.85 \pm 0.37$ and $2.64 \pm 0.35$, respectively; $\mathrm{P}<0.05$; Fig. 3D). Collectively, these results indicated that miR-200a expression was decreased in NSCLC, suggesting that miR-200a serves a role in NSCLC by targeting HGF. To confirm this hypothesis, miR-200a mimics and the corresponding negative controls were transfected into H1299 cells for $48 \mathrm{~h}$. The RT-qPCR results demonstrated that HGF expression was significantly reduced following transfection of miR-200a mimics compared with the control $(0.3 \pm 0.08$; $\mathrm{P}<0.05)$, whereas miR-141 had no significant effect on HGF expression (Fig. 3E). To confirm this result, an HGF-3'-UTR 
A

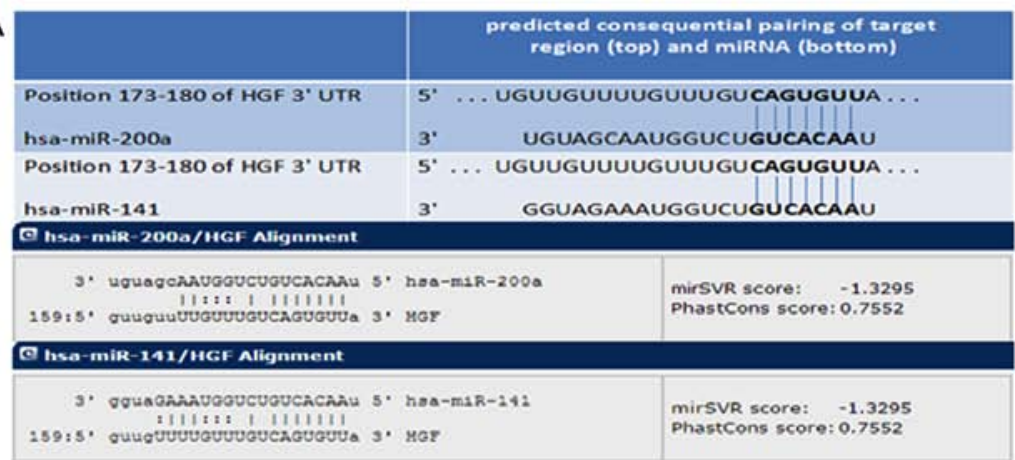

C

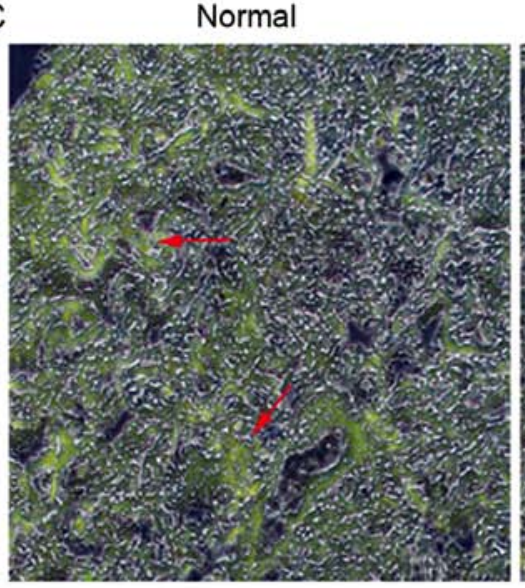

NSCLC

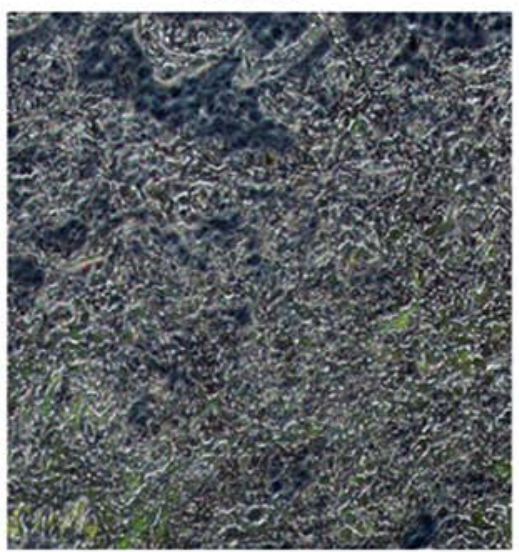

E

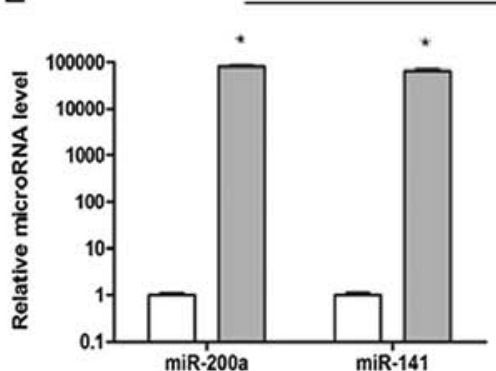

H1299+miRNAs

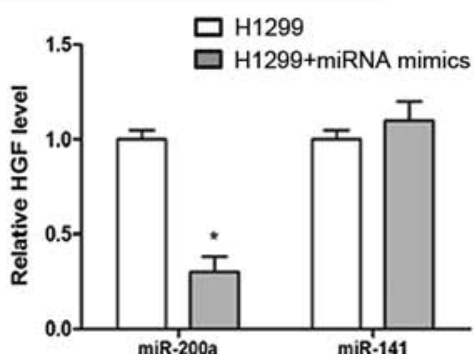

B

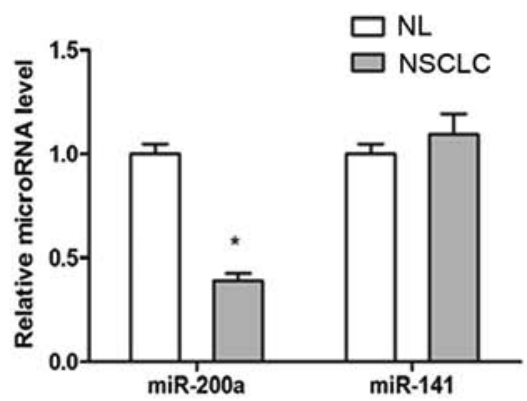

D
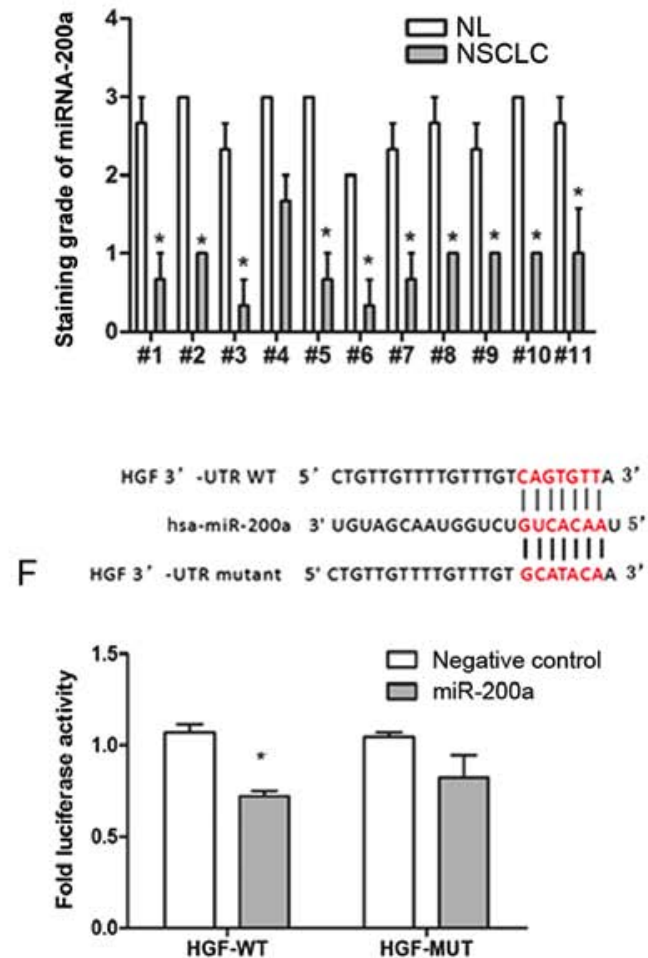

Figure 3. HGF is the target gene of miR-200a. (A) The websites http://www.targetscan.org/ and http://www.microrna.org/ predicted that the conserved sequence of miR-200a and miR-141 has a binding site with the HGF 3'-UTR region. (B) Reverse transcription-quantitative polymerase chain reaction results demonstrated that the expression level of miR-200a was significantly decreased in NSCLC samples compared within normal lung tissues. "P<0.05 NSCLC vs. con. (C) Images (magnification x40) and (D) in situ hybridization staining analysis confirmed that the expression level of miR-200a was significantly lower in NSCLC samples ( $\mathrm{n}=11)$ compared with normal lung tissues. "P<0.05 NSCLC vs. con. (E) H1299 cells were successfully transfected with miR-200a and miR-141. ${ }^{*} \mathrm{P}<0.05$ miRNAs vs. con. The HGF expression level significantly decreased following miR-200a transfection. ${ }^{*} \mathrm{P}<0.05 \mathrm{miR}-200 \mathrm{a}$ vs. con. (F) Dual-Luciferase reporter assay verified that miR-200a can bind to the HGF 3'-UTR. "P<0.05 HGF-WT+miR-200a vs. con. UTR, untranslated region; HGF, hepatocyte growth factor; si, small interfering; NSCLC, non-small cell lung cancer; NL, normal lung; miR, microRNA; WT, wild-type; MUT, mutant.

Dual-Luciferase reporter vector and mock vector was constructed and co-transfected them into H1299 cells with miR-200a mimics/control for $48 \mathrm{~h}$. As presented in Fig. 3F, the HGF-WT image intensity was significant weaker in miR-200a mimics compared within the control $(\mathrm{P}<0.05)$. Taken together, these data imply that reduced expression of miR-200a and increased expression of HGF in NSCLC tissues are due to the miR-200a-mediated negative regulation of HGF expression (Fig. 3F).

miRNA-200a reduces the migration and invasion of NSCLC cells by negatively regulating HGF expression. miR-200a is a negative regulator of HGF and is significantly associated with HGF expression in NSCLC; however, how miR-200a affects the development of NSCLC by targeting HGF remains unclear. Migration and invasion are two major characteristics of malignancies. Therefore, the expression of associated proteins was assessed by western blot analysis of A549 and H1299 cells transfected with miR-200a mimics and control. As presented in Fig. 4A, following miR-200a overexpression in cells by transfection for $48 \mathrm{~h}$ (Fig. 3E), the HGF protein band was weaker in the miR-200a mimics group compared with the control (Fig. 4A). The HGF protein expression level was significantly decreased to $0.34 \pm 0.09$ and $0.63 \pm 0.15$ in A549 and $\mathrm{H} 1299$ cells $(\mathrm{P}<0.05$; Fig. 4B) as determined by protein band gray value analysis. A similar c-Met protein expression 

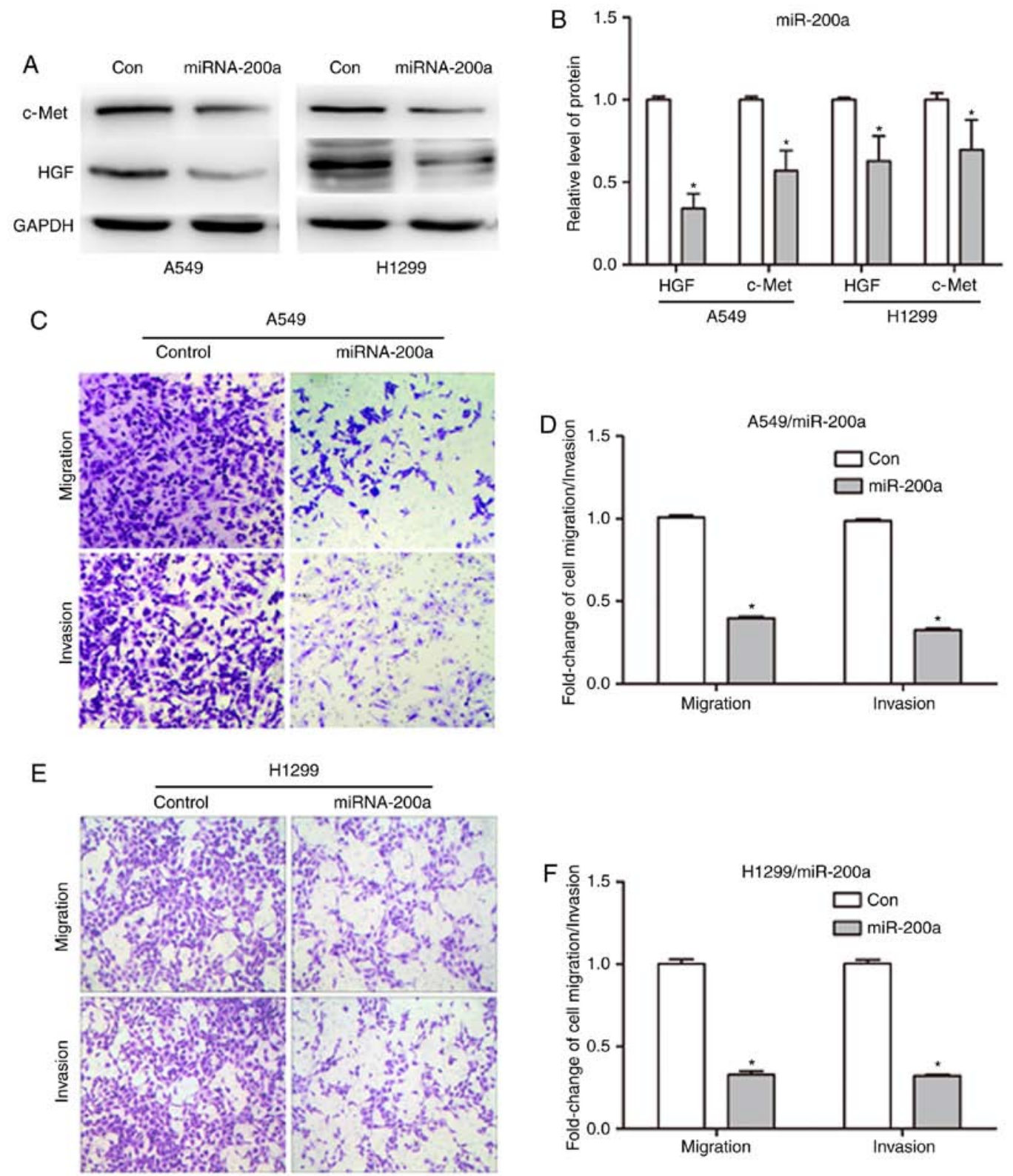

Figure 4. Upregulation of miR-200a reduces the migration and invasion of NSCLC cells. (A) Western blotting and (B) quantitative analysis revealed that the expression levels of HGF and its receptor c-Met were significantly decreased in A549 and H1299 cells following transfection of miR-200a. "P<0.05 miRNA-200a vs. con. (C) Images and (D) quantitative analysis of Transwell assays demonstrated that the migration and invasion of A549 cells were inhibited following transfection with miR-200a. "P $<0.05$ miRNA-200a vs. con. (E and F) Transwell assays demonstrated that the migration and invasion of H1299 cells were inhibited following transfection with miR-200a "P<0.05 miRNA-200a vs. con. HGF, hepatocyte growth factor; si, small interfering; NSCLC, non-small cell lung cancer; Con, control; miR, microRNA.

trend was observed in the miR-200a mimics group compared with the control group (Fig. 4A and B).

Since the upregulation of miR-200a reduced HGF and c-Met expression, the migration and invasion of A549 and H1299 cells was examined next following miR-200a overexpression by Transwell experiments. As presented in Fig. 4C, the number of migrated and invaded cells was decreased in the miR-200a mimics A549 group compared with the control group (Fig. 4C). The migration and invasion rates were significantly reduced to $39.8 \pm 1.64$ and $32.6 \pm 1.70 \%$, respectively in the miR-200a transfected A549 group compared with the control $(\mathrm{P}<0.05$ and $\mathrm{P}<0.05$; Fig. 4D). Next, whether the reduction of migration and invasion was unique to A549 cells was verified. The results were similar in the H1299 cell line. Crystal violet staining demonstrated in Fig. 4C indicated that the number of migrated and invaded cells was decreased in the miR-200a mimics H1299 group (Fig. 4E). The migration and invasion rates were significantly reduced to $32.8 \pm 4.0$ and $32.2 \pm 0.98 \%$ in the miR-200a H1299 group $(\mathrm{P}<0.05$ and $\mathrm{P}<0.05$; Fig. 4F). Collectively, these results indicated that miR-200a serves an important role in regulating NSCLC migration and invasion by negatively regulating HGF expression.

High miR-200a and low HGF expression promote DNA double strand breaks (DSBS) and apoptosis, and inhibits colony formation in NSCLC cells in response to irradiation. Chemoradiation therapy is one of the main treatment methods 


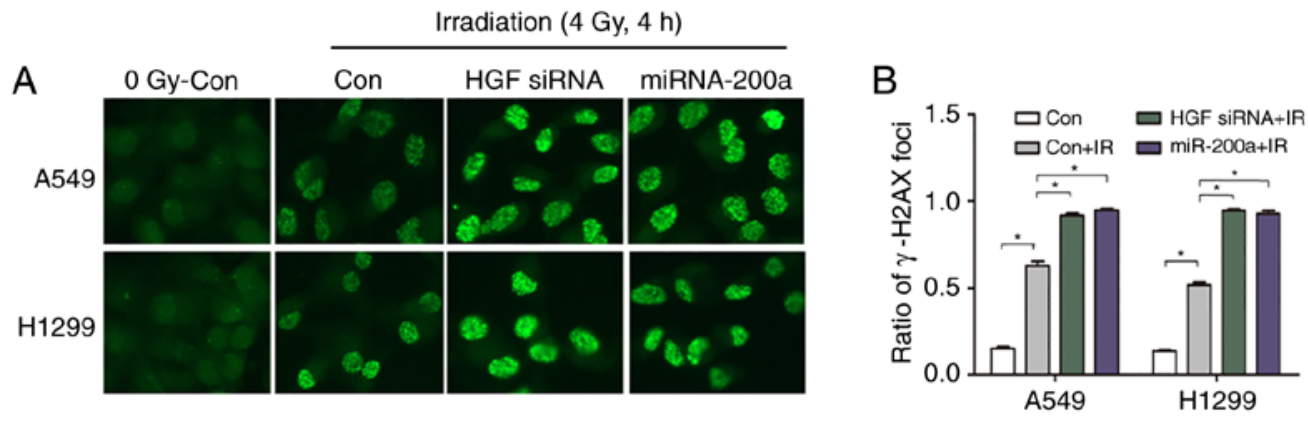

C
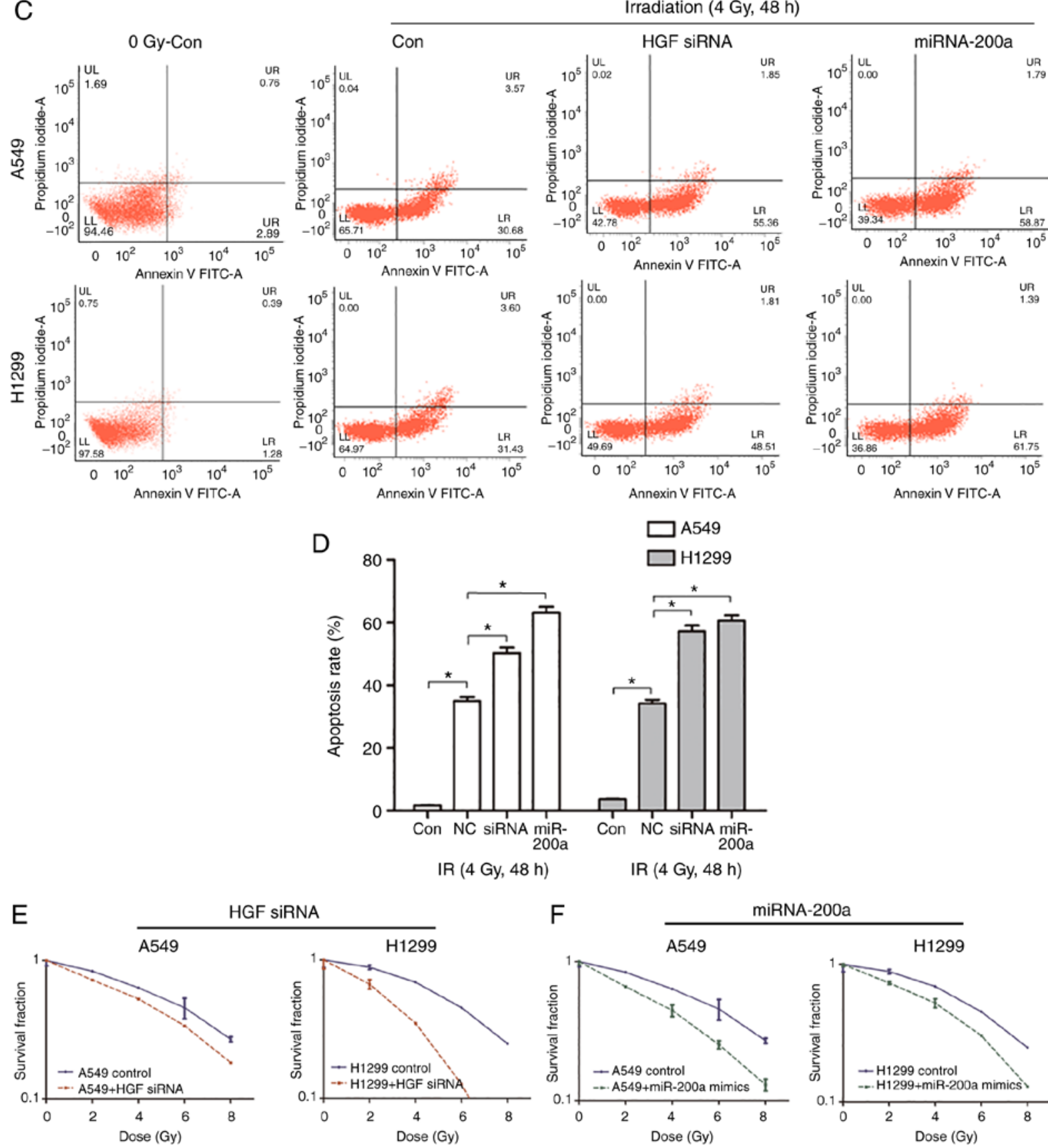

HGF siRNA

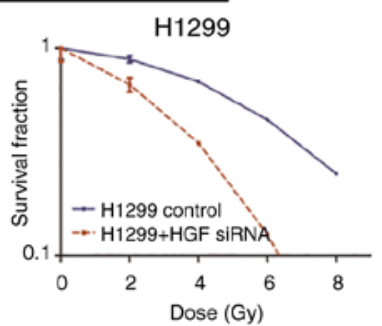

F miRNA-200a

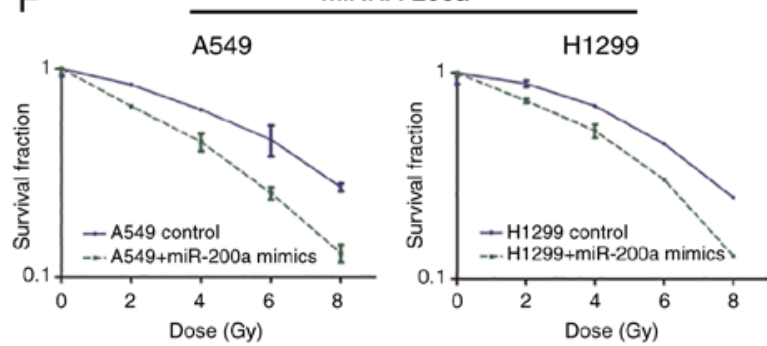

Figure 5. High miR-200a and low HGF expression promotes apoptosis, DNA double strand breaks, and inhibits the cloning rate of NSCLC cells following irradiation. (A and B) immunofluorescence detection of $\gamma$-H2AX foci in miR-200a transfected or siRNA HGF-transfected A549 and H1299 cells treated with or without irradiation. Magnification, $x 100$. "P<0.05 con+IR vs. con. At $4 \mathrm{~h}$ following irradiation, the rates of $\gamma-\mathrm{H} 2 \mathrm{AX}$ foci in miR-200a mimics. ${ }^{*} \mathrm{P}<0.05$ miR-200a+IR vs. con+IR or HGF siRNA. "P<0.05, HGF siRNA+IR vs. con+IR. Transfected cells were higher than in negative cells. (C and D) Flow cytometric analysis results demonstrated that the rates of apoptosis of miR-200a mimics. ${ }^{*} \mathrm{P}<0.05 \mathrm{miR}-200 \mathrm{a}$ vs. con+IR or HGF siRNA, $\mathrm{P}<0.05 \mathrm{HGF}$ siRNA vs. con+IR transfected cells were significantly increased compared with negative cells at $48 \mathrm{~h}$ following irradiation. The colony formation experiment results demonstrated that the radiosensitivity of A549 and H1299 cells was enhanced following transfection of (E) siRNA ("P<0.05 HGF siRNA vs. con+IR) or (F) miR-200a mimics. "P<0.05 miR-200a vs. con +IR. HGF, hepatocyte growth factor; si, small interfering; NSCLC, non-small cell lung cancer; Con, control; miR, microRNA; IR, ionizing radiation. 
for advanced NSCLC. Histone H2AX on serine 139 phosphorylation $(\gamma-\mathrm{H} 2 \mathrm{AX})$ was selected as the DNA DSB marker to assess the effect of the miR-200a/HGF pathway on DNA damage and repair following exposure of A549 and H1299 cells to X-ray radiation. Following transfection of miR-200a mimics and control, A549 and H1299 cells were cultured for $48 \mathrm{~h}$ and exposed to $4 \mathrm{~Gy} \mathrm{X}$-rays. Cells were fixed after $4 \mathrm{~h}$ and subjected to immunofluorescence assays with the anti- $\gamma-\mathrm{H} 2 \mathrm{AX}$ antibody (Fig. 5A). Compared with the control IR group, the miR-200a mimics group formed more $\gamma$-H2AX foci (Fig. 5A). Compared with the control group, the $\gamma$-H2AX foci number in the miR-200a mimics group was significantly $1.51-$ and 1.79 -fold increased $(\mathrm{P}<0.05$; Fig. $5 \mathrm{~B})$. To confirm that the increase in $\gamma$-H2AX foci was caused by the downregulation of HGF expression, HGF siRNA or mock was directly transfected into A549 and H1299 cells and immunofluorescence assays were performed. The results of transfection of miR-200a mimics and siRNA HGF were similar, which resulted in a greater number of $\gamma-\mathrm{H} 2 \mathrm{AX}$ foci compared with the control group (Fig. 5A). The $\gamma$-H2AX foci number was significantly 1.46 - and 1.82 -fold increased in the A549 and H1299 siRNA HGF groups compared within the control group $(\mathrm{P}<0.05 ;$ Fig. $5 \mathrm{~B})$. This suggested that miR-200a downregulated HGF expression and inhibited the DNA DSB repair pathway, resulting in a higher number of DSBs. Next, whether the miR-200a upregulation-induced DSBs increased the cell death rate was tested. An Annexin-PI cell apoptosis kit was used to assess the apoptosis rate in miR-200a-transfected A549 and H1299 cells following exposure to 4 Gy irradiation and recovery for $48 \mathrm{~h}$. Compared with the mock group, the miR-200a mimics group exhibited a significantly higher apoptosis rate (Fig. 5C) by 1.8- and 1.7-fold (P<0.05; Fig. 5D). The same assay was performed in HGF siRNA transfected cells. As presented in Fig. 5C and D, the apoptosis rate was 1.44and 1.67-fold increased in the siRNA HGF group compared with the mock group. In addition, transfection of miR-200a or HGF siRNA or control into A549 and H1299 cells was used to investigate radiosensitivity by comparing colony formation rate at radiation doses of $0,2,4,6$ and $8 \mathrm{~Gy}$. The survival curves demonstrated that HGF siRNA or miR-200a mimics transfected A549 and H1299 groups were more radiosensitive than the corresponding control groups (Fig. 5E and F). These results indicated that miR-200a serves a key role in regulating NSCLC cell radiosensitivity by targeting HGF in response to irradiation.

\section{Discussion}

Lung cancer remains the leading cause of cancer-associated mortality (2). Approximately 70\% of NSCLC patients present with locally advanced (clinical III) or metastatic disease at the time of diagnosis. Identifying the regulatory molecules and the underlying mechanism is important for improving our understanding of NSCLC and developing novel treatments. In the present study, it was demonstrated that HGF, a key c-Met growth pathway regulator, was associated with NSCLC compared with normal clinical samples. HGF is an autocrine and paracrine secretory factor that serves critical roles in cell dissociation, migration, proliferation and differentiation by targeting the c-Met receptor. The results of the present study identified HGF as a potential marker for NSCLC. HGF serves important roles through its secretion into the tumor microenvironment and the activation of c-Met and downstream effectors. HGF and its receptor c-Met serve important roles in regulating cell proliferation. Overexpression of HGF has been reported in a variety of types of human cancers, including NSCLC, renal, breast, ovarian cancer and pleural mesothelioma (5). Its high level of expression represents an unfavorable prognostic factor $(6,7)$. Therefore, focusing on the HGF status and regulation in tumors is important to further develop novel therapeutic strategies. In the present study, evidence was provided that the HGF expression level was correlated with NSCLC tumor malignancy $(10,28)$.

Concurrent radio-chemotherapy is the indicated treatment for patients with NSCLC. Whether HGF expression affects cancer radioresistance and its potential applications in radiotherapy remain unclear. Ionizing radiation (IR) could activate HGF and c-Met expression and signaling cascades, which serve critical roles in promoting proliferation, invasion and resistance to apoptosis $(29,30)$. Analysis of HGF and Met expression in 205 pre-menopausal and 184 post-menopausal patients randomized to receive chemo- or radiotherapy demonstrated that higher HGF or metexpression in breast cancer patients was associated with a better response to radiotherapy (31). Saigusa et al (32) demonstrated that inhibition of radiation-induced HGF upregulation and blockade of autocrine/paracrine $\mathrm{HGF} / \mathrm{c}-\mathrm{Met}$ signaling are potential novel strategies for controlling distant recurrence in rectal cancer patients following preoperative chemoradiotherapy. These findings indicate that HGF is important for cancer radiotherapy research and application. HGF and its receptor c-Met are overexpressed in NSCLC, and their overexpression is associated with poor prognosis in patients with NSCLC (33-35). The present study also demonstrated that HGF expression was increased in NSCLC samples compared within normal lung tissues. Several studies demonstrated that activation of the HGF/c-Met signaling pathway not only promotes invasiveness and distant metastasis in cancer, but also increases the radioresistance of cancer $(36,37)$. The present study revealed that the silencing of HGF in A549 and H1299 lung cancer cells inhibited their migration and invasion and enhanced their radiosensitivity. Furthermore, the inhibition of HGF expression promoted apoptosis and DNA DSBs in lung cancer cells following irradiation. The results indicated that the HGF/c-Met signaling pathway may be an effective target for increasing the radiosensitivity of lung cancer.

In recent years, an increasing number of studies have demonstrated that several inhibitors can specifically target HGF/c-Met in various types of cancer $(38,39)$. Several c-Met inhibitors are currently under clinical studies $(40,41)$. In addition, HGF analogues, anti-HGF humanized antibodies and c-Met induced receptor antibodies directed against the c-Met extracellular domain are being used to prevent HGF-specific binding and activation of c-Met $(42,43)$. Inhibition of HGF/c-Met signaling can also be achieved by using selective c-Met small molecule tyrosine kinase inhibitors (TKIs) or nonselective receptor TKIs. However, these methods have their own limitations. For example, TKIs primarily inhibit tyrosine kinase sites, not just only c-Met tyrosine kinases (44). Therefore, additional treatment methods need to be identified. 
In the last decade, the biological actions of miRNAs have attracted much attention. A number of studies demonstrated that miRNAs serve an important role in tumor pathogenesis and provided novel insights into the biology of radiotherapy (45-47). In the present study, miRNAs associated with NSCLC that function in negatively regulating HGF expression was identified. miR-200a and miR-141 were associated with NSCLC. Furthermore, miR-200a negatively regulated HGF expression in the present study's experiments. miR-200a belongs to the miR-200 family and miR-200adependent signaling is associated with improved survival rates of patients (48). In the present study, it was demonstrated that transfection of miR-200a mimics inhibited the migration and invasion of A549 and H1299 cells and increased radiosensitivity compared with the corresponding control cells. Similar to the results of HGF downregulation, following radiation, the apoptosis and DNA DSBs of these NSCLC cells were increased by miR-200a overexpression.

Although the potential for miR-200a in clinical applications was identified, how to achieve the same expression in vivo requires further investigation. Certain studies demonstrated that xenografts can be used to upregulate specific miRNAs for radiosensitization in vivo. In clinically relevant studies, the delivery of synthetic miRNAs as tumor suppressors was tested to develop alternative therapies $(49,50)$. For example, the use of liposomal nanoparticles containing miR-200c mimics was tested in animal lung cancer models and this method can increase tumor radiosensitivity by regulating cellular oxidative stress (51). Therefore, the application of miR-200a to clinical treatment may be achieved in the future.

In conclusion, the present study demonstrated that HGF is one of the target genes of miR-200a and miR-200a can inhibit migration and invasion, increase the apoptosis rate and $\gamma$-H2AX foci, and enhance the radiosensitivity of NSCLC cells by inhibiting the HGF/c-Met signaling pathway. miR-200a could therefore be used as a potential radiosensitization molecule in clinical practice.

\section{Acknowledgements}

Not applicable.

\section{Funding}

The present study was supported by grants from the Jiangsu Provincial Natural Science Foundation Project (grant no. BK20141185), the Shanghai Natural Science Foundation Project (grant no. 17ZR1406100) and the Fudan University Shanghai Cancer Center Foundation Project (grant no. YJRC1601).

\section{Availability of data and materials}

The datasets generated during the present study are available from the corresponding author on reasonable request.

\section{Authors' contributions}

MD completed all trial procedures, data analysis and was a major contributor in writing the manuscript. JW was involved in the collection and processing of human lung cancer specimens. HC screened the microRNAs and organized the patient-related pathology data. SW guided the histopathological study of immunohistochemistry, the in situ hybridization and all the methods and ideas of cell experiments. LC provided solutions and detailed operations for ionizing radiation, provided the accelerator use rights, control and calculation of radiation dose. YX participated in the completion of the PCR and the in situ hybridization test procedures, and participated in the cultivation of cells. XL and FS designed the overall idea of the experiment and provided theoretical guidance throughout the process, and participated in the revision of the manuscript and the processing of data. All authors read and approved the manuscript and agree to be accountable for all aspects of the research in ensuring that the accuracy or integrity of any part of the work are appropriately investigated and resolved.

\section{Ethics approval and consent to participate}

The present study was approved by the Ethics Committee of the Second Affiliated Hospital of Soochow University (Suzhou, China) and written informed consent was provided by all patients.

\section{Patient consent for publication}

Written informed consent was provided by all patients.

\section{Competing interests}

The authors declare that there is no conflict of interest regarding the publication of this paper.

\section{References}

1. Chen W, Zheng R, Baade PD, Zhang S, Zeng H, Bray F, Jemal A, $\mathrm{Yu}$ XQ and He J: Cancer statistics in China, 2015. CA Cancer J Clin 66: 115-132, 2016.

2. Siegel RL, Miller KD and Jemal A: Cancer statistics, 2015. CA Cancer J Clin 65: 5-29, 2015.

3. Torre LA, Bray F, Siegel RL, Ferlay J, Lortet-Tieulent J and Jemal A: Global cancer statistics, 2012. CA Cancer J Clin 65: 87-108, 2015

4. Molina JR, Yang P, Cassivi SD, Schild SE and Adjei AA: Non-small cell lung cancer: Epidemiology, risk factors, treatment, and survivorship. Mayo Clin Proc 83: 584-594, 2008.

5. Blumenschein GR Jr, Mills GB and Gonzalez-Angulo AM: Targeting the hepatocyte growth factor-cMET axis in cancer therapy. J Clin Oncol 30: 3287-3296, 2012.

6. Kim YJ, Go H, Wu HG, Jeon YK, Park SW and Lee SH: Immunohistochemical study identifying prognostic biomolecular markers in nasopharyngeal carcinoma treated by radiotherapy. Head Neck 33: 1458-1466, 2011.

7. Raghav KP, Wang W, Liu S, Chavez-MacGregor M, Meng X, Hortobagyi GN, Mills GB, Meric-BernstamF, Blumenschein GR Jr and Gonzalez-Angulo AM: cMET and phospho-cMET protein levels in breast cancers and survival outcomes. Clin Cancer Res 18: 2269-2277, 2012

8. Preusser M, Streubel B, Berghoff AS, Hainfellner JA, von Deimling A, Widhalm G, Dieckmann K, Wöhrer A, Hackl M, Zielinski $\mathrm{C}$ and Birner P: Amplification and overexpression of CMET is a common event in brain metastases of non-small cell lung cancer. Histopathology 65: 684-692, 2014.

9. Bhardwaj V, Cascone T, Cortez MA, Amini A, Evans J, Komaki RU, Heymach JV and Welsh JW: Modulation of c-Met signaling and cellular sensitivity to radiation: Potential implications for therapy. Cancer 119: 1768-1775, 2013. 
10. Firtina Karagonlar Z, Koc D, Iscan E, Erdal E and Atabey N: Elevated hepatocyte growth factor expression as an autocrine c-Met activation mechanism in acquired resistance to sorafenib in hepatocellular carcinoma cells. Cancer Sci 107: 407-416, 2007.

11. Xie LQ, Bian LJ, Li Z, Li Y and Liang YJ: Co-elevated expression of hepatocyte growth factor and Interleukin-8 contributes to poor prognosis of patients with primary nasopharyngeal carcinoma. Oncol Rep 23: 141-150, 2010.

12. Sipos F, Galamb O, Herszényi L, Molnár B, Solymosi N, Zágoni T, Berczi L and Tulassay Z: Elevated insulin-like growth factor 1 receptor, hepatocyte growth factor receptor and telomerase protein expression in mild ulcerative colitis. Scand J Gastroenterol 43: 289-298, 2008

13. Okazaki M, Yoshimura K, Uchida G and Harii K: Elevated expression of hepatocyte and keratinocyte growth factor in cultured buccal-mucosa-derived fibroblasts compared with normal-skin-derived fibroblasts. J Dermatol Sci 30: 108-115, 2002.

14. Bartel DP: MicroRNAs: Genomics, biogenesis, mechanism, and function. Cell 116: 281-297, 2004.

15. Lewis BP, Burge CB and Bartel DP: Conserved seed pairing, often flanked by adenosines, indicates that thousands of human genes are microRNA targets. Cell 120: 15-20, 2005.

16. Liu Y, Li M, Zhang G and Pang Z: MicroRNA-10b overexpression promotes non-small cell lung cancer cell proliferation and invasion. Eur J Med Res 18: 41, 2013.

17. Huang Y, Shen XJ, Zou Q, Wang SP, Tang SM and Zhang GZ: Biological functions of microRNAs: A review. J Physiol Biochem 67: 129-139, 2011.

18. Lages E, Ipas H, Guttin A, Nesr H, Berger F and Issartel JP MicroRNAs: Molecular features and role in cancer. Front Biosci (Landmark Ed) 17: 2508-2540, 2012.

19. Croce CM: Causes and consequences of microRNA dysregulation in cancer. Nat Rev Genet 10: 704-714, 2009

20. Kasinski AL and Slack FJ: Epigenetics and genetics. MicroRNAs en route to the clinic: Progress in validating and targeting microRNAs for cancer therapy. Nat Rev Cancer 11: 849-864, 2011.

21. Li J, Tan Q, Yan M, Liu L, Lin H, Zhao F, Bao G, Kong H, Ge C, Zhang F, et al: miRNA-200c inhibits invasion and metastasis of human non-small cell lung cancer by directly targeting ubiquitin specific peptidase 25. Mol Cancer 13: 166, 2014.

22. Yu T, Li J, Yan M, Liu L, Lin H, Zhao F, Sun L, Zhang Y, Cui Y, Zhang F, et al: MicroRNA-193a-3p and -5p suppress the metastasis of human non-small-cell lung cancer by downregulating the ERBB4/PIK3R3/mTOR/S6K2 signaling pathway. Oncogene 34: 413-423, 2015.

23. Wang R, Chen DQ, Huang JY, Zhang K, Feng B, Pan BZ, Chen J, De W and Chen LB: Acquisition of radioresistance in docetaxel-resistant human lung adenocarcinoma cells is linked with dysregulation of $\mathrm{miR}-451 / \mathrm{c}-\mathrm{Myc}$-survivin/rad-51 signaling. Oncotarget 5: 6113-6129, 2014

24. Montoya V, Fan H, Bryar PJ, Weinstein JL, Mets MB, Feng G, Martin J, Martin A, Jiang H and Laurie NA: Novel miRNA-31 and miRNA-200a-mediated regulation of retinoblastoma proliferation. PLoS One 10: e0138366, 2015.

25. Yang JJ, Tao H, Hu W, Liu LP, Shi KH, Deng ZY and Li J: MicroRNA-200a controls Nrf2 activation by target Keap1 in hepatic stellate cell proliferation and fibrosis. Cell Signal 26 2381-2389, 2014

26. Liu YY, Chen MB, Cheng L, Zhang ZQ, Yu ZQ, Jiang Q, Chen G and Cao C: microRNA-200a downregulation in human glioma leads to Gail over-expression, Akt activation, and cell proliferation. Oncogene 37: 2890-2902, 2018.

27. Livak KJ and Schmittgen TD: Analysis of relative gene expression data using real-time quantitative PCR and the 2(-Delta Delta C(T)) Method. Methods 25: 402-408, 2001.

28. Blum D and LaBarge S; Reproducibility Project: Cancer Biology: Registered report: Tumour micro-environment elicits innate resistance to RAF inhibitors through HGF secretion. Elife 3, e04034, 2014. doi:10.7554/eLife.04034.

29. Rivera M, Sukhdeo K and Yu J: Ionizing radiation in glioblastoma initiating cells. Front Oncol 3: 74, 2013.

30. De Bacco F, Luraghi P, Medico E, Reato G, Girolami F, Perera T, Gabriele P, Comoglio PM and Boccaccio C: Induction of MET by ionizing radiation and its role in radioresistance and invasive growth of cancer. J Natl Cancer Inst 103: 645-661, 2011

31. Veenstra C, Pérez-Tenorio G, Stelling A, Karlsson E, Mirwani SM, Nordensköljd B, Fornander T and Stål O: Met and its ligand HGF are associated with clinical outcome in breast cancer. Oncotarget 7: 37145-37159, 2016.
32. Saigusa S, Toiyama Y, Tanaka K, Yokoe T, Fujikawa H, Matsushita K, Okugawa Y, Inoue Y, Uchida K, Mohri Y and Kusunoki M: Inhibition of HGF/cMET expression prevents distant recurrence of rectal cancer after preoperative chemoradiotherapy. Int J Oncol 40: 583-591, 2012.

33. Hosoda H, Izumi H, Tukada Y, Takagiwa J, Chiaki T, Yano M and Arai H: Plasma hepatocyte growth factor elevation may be associated with early metastatic disease in primary lung cancer patients. Ann Thorac Cardiovasc Surg 18: 1-7, 2012.

34. Navab R, Liu J, Seiden-Long I, Shih W, Li M, Bandarchi B, Chen Y, Lau D, Zu YF, Cescon D, et al: Co-overexpression of Met and hepatocyte growth factor promotes systemic metastasis in NCI-H460 non-small cell lung carcinoma cells. Neoplasia 11: 1292-1300, 2009.

35. Chen Y, Du M, Wang J, Xing P, Zhang Y, Li F and Lu X: MiRNA-200a expression is inverse correlation with hepatocyte growth factor expression in stromal fibroblasts and its high expression predicts a good prognosis in patients with non-small cell lung cancer. Oncotarget 7: 48432-48442, 2016.

36. Jankowski K, Kucia M, Wysoczynski M, Reca R, Zhao D, Trzyna E, Trent J, Peiper S, Zembala M, Ratajczak J, et al: Both hepatocyte growth factor (HGF) and stromal-derived factor-1 regulate the metastatic behavior of human rhabdomyosarcoma cells, but only HGF enhances their resistance to radiochemotherapy. Cancer Res 63: 7926-7935, 2003.

37. Sylvester PW: Targeting met mediated epithelial-mesenchymal transition in the treatment of breast cancer. Clin Transl Med 3: 30, 2014.

38. Kou J, Musich PR, Staal B, Kang L, Qin Y, Yao ZQ, Zhang B, Wu W, Tam A, Huang A, et al: Differential responses of MET activations to MET kinase inhibitor and neutralizing antibody. J Transl Med 16: 253, 2018.

39. Cruickshanks N, Zhang Y, Hine S, Gibert M, Yuan F, Oxford M, Grello CM, Pahuski M, Dube C, Guessous F, et al: Discovery and therapeutic exploitation of mechanisms of resistance to MET inhibitors in glioblastoma. Clin Cancer Res: September 10, 2018 (Epub ahead of print). doi: 10.1158/1078-0432.CCR-18-0926.

40. Aliebrahimi S, Montasser Kouhsari S, Ostad SN, Arab SS and Karami L: Identification of phytochemicals targeting c-Met kinase domain using consensus docking and molecular dynamics simulation studies. Cell Biochem Biophys 76: 135-145, 2018.

41. Liu X, Kou J, Xiao Z, Tian F, Hu J, Zheng P and Zhu W: Design, synthesis and biological evaluation of 6,7-disubstituted-4-phenoxyquinoline derivatives bearing pyridazinone moiety as c-Met inhibitors. Molecules 23: E1543, 2018.

42. Harshman LC and Choueiri TK: Targeting the hepatocyte growth factor/c-Met signaling pathway in renal cell carcinoma. Cancer J 19: 316-323, 2013.

43. Peters $S$ and Adjei AA: MET: A promising anticancer therapeutic target. Nat Rev Clin Oncol 9: 314-326, 2012.

44. Utsugi $\mathrm{T}$ : New challenges and inspired answers for anticancer drug discovery and development. Jpn J Clin Oncol 43: 945-953, 2013.

45. Redis RS, Berindan-Neagoe I, Pop VI and Calin GA: Non-coding RNAs as theranostics in human cancers. J Cell Biochem 113: 1451-1459, 2012

46. Cherni I and Weiss GJ: miRNAs in lung cancer: Large roles for small players. Future Oncol 7: 1045-1055, 2011.

47. Du L and Pertsemlidis A: microRNA regulation of cell viability and drug sensitivity in lung cancer. Expert Opin Biol Ther 12: 1221-1239, 2012.

48. Mateescu B, Batista L, Cardon M, Gruosso T, de Feraudy Y, Mariani O, Nicolas A, Meyniel JP, Cottu P, Sastre-Garau X and Mechta-Grigoriou F: miR-141 and miR-200a act on ovarian tumorigenesis by controlling oxidative stress response. Nat Med 17: 1627-1635, 2011.

49. Wang X andLiGH:MicroRNA-16 functions as a tumor-suppressor gene in oral squamous cell carcinoma by targeting AKT3 and BCL2L2. J Cell Physiol 233: 9447-9457, 2018.

50. Sun GL, Li Z, Wang WZ, Chen Z, Zhang L, Li Q, Wei S, Li BW, $\mathrm{Xu} \mathrm{JH}$, Chen L, et al: miR-324-3p promotes gastric cancer development by activating Smad4-mediated Wnt/beta-catenin signaling pathway. J Gastroenterol 53: 725-739, 2018.

51. Cortez MA, Valdecanas D, Zhang X, Zhan Y, Bhardwaj V, Calin GA, Komaki R, Giri DK, Quini CC, Wolfe T, et al: Therapeutic delivery of miR-200c enhances radiosensitivity in lung cancer. Mol Ther 22: 1494-1503, 2014.

This work is licensed under a Creative Commons

Attribution-NonCommercial-NoDerivatives 4.0 International (CC BY-NC-ND 4.0) License. 